\title{
CONFIGURAÇÃO VERBO-VISUAL E ESTRATÉGIAS DE RECONTEXTUALIZAÇÃO EM PROPOSTAS DE REDAÇÃO DO ENEM ${ }^{1}$
}

\author{
Francisco Jeimes de Oliveira Paiva*
}

\begin{abstract}
RESUMO: Esta pesquisa investigou o processo de recontextualização de textos verbo-visuais em redações-modelo a partir da análise da composição multimodal das propostas de redação do Enem. Essas propostas têm focalizado competências e habilidades básicas que são estimuladas e transformadas pelas práticas de letramento visual crítico (ler, ver, visualizar, pensar, interpretar e comunicar), necessárias para a produção dos múltiplos significados sociais através da verbo-visualidade dos textos disponíveis nessas propostas. Esta pesquisa, fundamenta-se em estudos sobre Multimodalidade e Letramento Visual, na Semiótica Social (HODGE e KRESS, 1988; KRESS e VAN LEEUWEN, [1996] 2006; KRESS, 2003, 2010), e nas categorias de análise - texto, prática social e prática discursiva, na Análise de Discurso Crítica (FAIRCLOUGH, 2001, 2003, 2006), contribuindo na análise e na categorização das estratégias de recontextualização discursiva (VAN LEEUWEN, 2008; TEIXEIRA, 2013) em um corpus de redações-modelo à luz dos enquadres teórico-metodológicos elencados. A análise dos dados e os resultados comprovaram que a composição multimodal das propostas de redação (2009 a 2016), estruturam-se de forma relativamente estável, porque demandaram dos/as participantes uma análise visual crítica das informações/fatos e opiniões para o desenvolvimento de argumentos produtivos, geralmente, recontextualizados por rearranjo e adição (VAN LEEUWEN, 2008), caracterizando-se, portanto, pela integração dos elementos semióticos que se organizaram e se alimentaram pelas práticas discursivas/sociais de linguagem e de produção semiótica de significados integrados.
\end{abstract}

PALAVRAS-CHAVE: Análise multimodal crítica. Recontextualização. Propostas de redação do Enem. Redações-modelo.

1 Resultado de pesquisa na linha: Ensino e Linguagens, no Mestrado Interdisciplinar em História e Letras (UECE/FECLESC) sob a orientação da Profa. Dra. Ana Maria Pereira Lima.

* Mestre em História e Letras pela Universidade Estadual do Ceará (UECE/FECLESC). Especialista em Ensino de Língua Portuguesa e Literaturas. Professor efetivo do Estado do Ceará/SEDUC. Membro do Grupo de Pesquisa - Práticas de Letramento, Gêneros Textuais e Formação Tecnológica do Professor. E-mail: geimesraulino@yahoo.com.br 


\title{
1 Imagens, discursos e textos verbais: algumas considerações iniciais
}

\author{
A riqueza e a diversidade dos gêneros do \\ discurso são infinitas porque são inesgotáveis \\ as possibilidades da multiforme atividade \\ bumana e porque em cada campo dessa ativi- \\ dade é integral o repertório de gêneros do dis- \\ curso, que cresce e se diferencia à medida que \\ se desenvolve e se complexifica um determi- \\ nado campo. \\ Bakhtin.
}

No Brasil, apesar de vivenciarmos inúmeras transformações no cenário com pesquisas da área das Ciências Humanas, Letras e Linguística, sobretudo no campo da Semiótica Social (SS), Análise de Discurso Crítica (ADC) e dos Novos Estudos de Letramento (NLS), ainda se percebe a necessidade de outros estudos para as muitas outras multissemioses oriundas da comunicação multimodal contemporânea.

Além do mais o contexto sócio-comunicativo e discursivo de interação humana e tecnológica hodierno está procurando ser capaz de moldar os comportamentos dos sujeitos sociais, visando maior apreensão da multiplicidade de semioses, de recontextualizações discursivas, além do uso de estratégias de leituras, escrita e significações sociais, perceptíveis, nas múltiplas linguagens presentes em uma sociedade tecnologizada (BUZATO, 2016).

No âmbito escolar, os/as professores/as estão enfrentando o desafio de adequar às práticas de ensino e os instrumentos avaliativos da aprendizagem com base em uma pedagogia crítica (PENNYCOOK, 2007)² e em uma pedagogia dos multiletramentos (New Group London - NGL, 1996) que possibilite a mediação e a adaptação pedagógica das aulas

\footnotetext{
${ }^{2}$ Uma pedagogia crítica busca compreender e criticar o contexto histórico e sociopolítico da escolarização, bem como desenvolver as práticas pedagógicas que buscam não só mudar a natureza da escolarização, mas também da sociedade mais ampla (PENNYCOOK, 2007, p. 42).
} 
às práticas de letramentos visuais/multimodais críticos, objetivando a melhoria das estratégias de ensino com atividades produtivas de leitura, escrita e produção de textos ${ }^{3}$.

Segundo Paiva e Lima (2018), tornou-se consensual entre linguistas, semioticistas e cientistas da linguagem que a "cultura contemporânea é sobretudo visual" (PELLEGRINI, 2003, p.15), a inclusão da imagem e de outros modos semióticos às pesquisas linguísticas ainda encontra muita resistência em certas abordagens mais tradicionais, ou seja, a ascensão de status dos gêneros discursivos multimodais como objeto dos estudos linguísticos só ocorreu recentemente (MOZDZENSKI, 2013), uma vez que a análise do discurso se restringiu a textos linguisticamente efetivados, valorizando-se a linguagem verbal nas modalidades oral e escrita, em razão de outros modos semióticos (KRESS, LEITE-GARCÍA; VAN LEEUWEN, 2000).

Nesse percurso, Mozdzenski (2013) revela que ainda que, em outras disciplinas, o exame dos signos já acontecesse desde os anos 1950/60, apenas nos últimos anos é que vem sendo alcançada no campo da Linguística uma pesquisa mais sistemática sobre o texto multimodal, abarcando conjuntamente os recursos semióticos que o compõem e consideram a sua inserção na chamada sociedade da imagem (KRESS; VAN LEEUWEN, 2001). Na leitura de Petermann (2005), é preciso problematizar o papel das imagens na comunicação, posto que a leitura de textos visuais/multimodais é desprezada na escola, implicando e produzindo, de acordo com Kress e van Leeuwen (2006, p. 1), “iletrados visuais".

Vale destacar que à eclosão de práticas e de eventos de letramentos na escola têm demandado o desenvolvimento de competênciast e habilidades ${ }^{5}$ dos discentes e docentes

\footnotetext{
${ }^{3}$ Vale destacar que "a leitura e a escrita precisam ser compreendidas como processos cognitivo, histórico, cultural e social e serem desenvolvidas em torno de alternativas voltadas para a reflexão crítica capaz de levar os alunos a ter participação ativa nas diferentes situações de aprendizagem por meio da ação e interação" (MACHADO, 2014, [p.7], paginação minha).

4 O MEC, em documento oficial, explica que o conceito de competência é assim considerado, são modalidades estruturais e estruturantes da inteligência, ou melhor, são ações e operações mentais ("saber aprender") que realizamos ao estabelecer relações com objetos, situações, fenômenos e pessoas, assim como as relações entre eles (BRASIL, 1998).

${ }^{5} \mathrm{O}$ que pode ser medido ou avaliado se refere às habilidades, conceito que de acordo com o MEC são ações e operações práticas decorrentes dos saberes transformado em competências. As habilidades demonstradas pelos 
quanto à leitura/escrita de textos verbo-visuais, pois os primeiros são sujeitos consumidores e produtores de textos, gêneros discursivos, necessitando apropriar-se das diversas estratégias em leitura e escrita multimodais em uma sociedade cujos processos de comunicação, produção e divulgação de conhecimentos, sobretudo, em espaços socioculturais, têm requerido muitas práticas de leitura e de escrita cada vez mais ubíquas e diversificadas diante da crescente inserção das tecnologias na educação básica (COSCARELLI et al, 2016).

Em suma, este artigo tem por objetivo principal: investigar o processo de recontextualização de textos verbo-visuais em textos verbais a partir da composição multimodal do gênero redação do Enem. Dessa forma, busquei captar os diversos aspectos desse estudo multimodal crítico, ancorei-me em um estudo de natureza qualitativa (DENZIN; LINCOLN, 2006), delineado pela técnica documental (CELLARD, 2008) e descritivo-interpretativista (ERICKSON, 1996; MOITA LOPES, 1996; 2006), alinhada aos estudos multimodais da linguística aplicada com base na ADC de Fairclough $(2001,2003)$ e na Semiótica Social com a GDV de Kress e van Leeuwen ([1996], 2006), entre outros, no sentido de possibilitar a verificação dos diversos aspectos de constituição semiótico-visual e de recontextualização discursiva das redações-modelo e de textos verbo-visuais, objetos de análise deste estudo.

\section{O Exame Nacional do Ensino Médio (Enem): como avaliação externa da Educa-} ção Básica no Brasil

Qualquer tentativa de reflexão e de análise da importância do Exame Nacional do Ensino Médio (Enem) perpassa primeiramente por uma perspectiva crítica de entender as condições de produção/recepção, o espaço comunicativo demandado por esta política educacional de avaliação de larga escala, bem como perceber os crescentes investimentos público-privados, além dos impactos dos indicadores de desempenho e dos resultados obtidos ao longo dessas últimas edições do exame (2009-2016), tornando o Enem em um 
instrumento valoroso para o acesso de estudantes às universidades públicas e privadas tanto no Brasil quanto em outros países que aceitam o desempenho no Enem como forma de ingresso ao Ensino Superior ${ }^{6}$.

O Exame Nacional do Ensino Médio (Enem) por se tratar de uma avaliação em larga escala representa um dos fatores que de certa maneira, condicionam a efetivação do currículo do Ensino Médio. Além do que se tornou desde sua criação em 1998, através da portaria $n^{\circ} 438$, de 28 de maio, uma das políticas públicas educacionais de maior envergadura no Brasil, ou seja, tornou-se o segundo maior exame educacional do mundo, colocando-se apenas atrás do que é realizado na China.

Além do mais, as provas no Enem foram estruturadas a partir de um relacionamento com a Matriz de Referência com competências e habilidades em consonância com os conteúdos curriculares do Ensino Médio. A matriz abarca as competências e habilidades indispensáveis e próprias ao jovem adulto que se encontra na etapa de desenvolvimento sócio-cognitivo correspondente ao término do ciclo da escolaridade da educação básica. Ademais, o Enem teve como base a Lei de Diretrizes e Bases da Educação Nacional (BRASIL, 1996), os Parâmetros Curriculares Nacionais (BRASIL, 1997) e as Diretrizes do Conselho Nacional de educação sobre a Educação Básica (BRASIL, 2001).

Em relação à prova de redação, coaduno com Salvador (2016) ao esclarecer acerca das dificuldades enfrentadas pelos/as participantes na atividade de Como escrever para o Enem - roteiro para uma redação nota 1000, essa autora assegura que "não há escapatória para aqueles 7 milhões de jovens no Enem - é escrever bem ou escrever bem” (SALVADOR,

\footnotetext{
${ }^{6}$ Para maiores informações, ver: https://www.estudarfora.org.br/nota-do-Enem-e-aceita-por-universidades-portuguesas/. Acesso em: 15 mar. 2018. Veja que a aceitação do Enem como método de seleção para instituições de ensino superior portuguesas começou em 2014, com a Universidade de Coimbra, que logo foi seguida pelas universidades do Algarve e da Beira Interior. "A decisão de usar as notas do Enem aconteceu em razão da qualidade do exame, que já está bem estabelecido no Brasil”, afirmou Joaquim Ramos de Carvalho, vice-reitor da Universidade de Coimbra, por meio de sua assessoria de imprensa.
} 
2016, p. 7) 7 , objetivando obter êxito entre os melhores resultados nas notas de redações no Exame.

Note-se que os objetivos traçados pelo exame ao longo das edições do Enem certamente rotulam como a prova de redação do Exame Nacional do Ensino Médio diferencia-se das provas de produção de texto dissertativo-argumentativo de outros exames porque estabelece a elaboração de uma proposta de intervenção para o problema apresentado pelo tema. Essa proposição vai ao encontro do que apregoam a Constituição Federal - CF e a Lei de Diretrizes e Bases - LDB no que converge aos seguintes objetivos da formação do estudante: o pleno desenvolvimento do educando e seu preparo para o exercício da cidadania (BRASIL, 1988; 1996).

Carvalho (2005, p. 112) evidencia que "[a] redação do Enem, assim como a parte objetiva da prova, é uma avaliação de competências", ressaltando, em seguida, que "a matriz de competências é devidamente adaptada, a fim de avaliar o desempenho do participante como produtor de um texto no qual ele demonstre capacidade de reflexão sobre o tema proposto". Nesse sentido, reafirmo que essa produção se constitui como objeto de estudo de pesquisadores/as das mais diversas áreas do conhecimento, sobretudo, da Linguística Textual e da Análise do Discurso, que investigam, entre outras questões, as concepções teóricas de gênero subjacentes à referida proposta de produção textual (REINALDO, 2002; PAULINELLI; FORTUNATO, 2016).

O desenvolvimento de toda essa "nova" cultura letrada proposta à educação linguística no Brasil, causou desde a elaboração do primeiro Guia do Participante: A redação no Enem ${ }^{8}$ para orientação dos participantes, em 2012, apresentando aos candidatos do Enem as Cinco Competências e Habilidades avaliadas na Prova de Redação, conforme ressalto no

\footnotetext{
${ }^{7}$ Sociolinguisticamente, a escolha de variedade linguística na escrita da Redação no Enem, dá-se pela norma padrão da Língua Portuguesa, uma vez que é a variedade de maior prestígio social, ditando normas e prescrevendo o que deve e não deve ser usado gramaticalmente, sobretudo a nível de formalidade na língua escrita.

${ }^{8}$ Disponível em: http://download.inep.gov.br/educacao_basica/Enem/downloads/2012/guia_participante_redacao_Enem2012.pdf. Acesso em: 18 mar. 2018.
} 
quadro abaixo, atualizado na Cartilha do Participante (BRASIL, 2017, p. 13), que se propõe "explicitar os critérios de avaliação", de maneira a auxiliar os/as candidatos/as a se prepararem para o exame.

Quadro 1 - Critérios de Avaliação com suas respectivas Competências e Habilidades do Enem

\begin{tabular}{|l|l|}
\hline Competência 1: & Demonstrar domínio da modalidade escrita formal da língua portuguesa. \\
\hline Competência 2: & $\begin{array}{l}\text { Compreender a proposta de redação e aplicar conceitos das várias áreas de } \\
\text { conhecimento para desenvolver o tema, dentro dos limites estruturais do texto } \\
\text { dissertativo-argumentativo em prosa. }\end{array}$ \\
\hline Competência 3: & $\begin{array}{l}\text { Selecionar, relacionar, organizar e interpretar informações, fatos, opiniões e } \\
\text { argumentos em defesa de um ponto de vista. }\end{array}$ \\
\hline Competência 5: & $\begin{array}{l}\text { Elaborar proposta de intervenção para o problema abordado, respeitando os } \\
\text { direitos humanos. }\end{array}$ \\
\hline
\end{tabular}

Fonte: BRASIL (2017, p. 8).

No quadro anterior, observo o quão necessária é a compreensão paulatina de cada competência a qual os/as candidatos/as têm suas redações avaliadas por dois ou mais avaliadores/as, que geralmente são licenciados/as ou bacharéis/bacharelas em Letras, capacitados/as para exercerem esse mister de forma analítica, criteriosa e crítica, primando pela qualidade da avaliação das redações, em conformidade com as temáticas trabalhadas, fundamentadas em orientações pedagógicas e normativas do MEC/INEP, sobretudo nas edições mais recentes de aplicação do Exame.

Por fim, em uma sociedade em que o acesso aos cursos de graduação costuma ser altamente valorizado, por ser percebido como caminho necessário para conquistar melhores empregos e, assim, ascender socialmente; os/as estudantes muito associam o sucesso escolar na educação básica à conquista de uma vaga em um curso de graduação; algo que, na atualidade, costuma ser atingido por intermédio de um bom desempenho nas provas do Enem (OLIVEIRA JÚNIOR, 2014, p. 4). 


\section{A perspectiva sobre o letramento visual/multimodal como prática social e discur-} siva na formação de sujeitos críticos

A Linguística Aplicada (LA), Análise do Discurso Crítica (ADC) e a Semiótica Social colocam em cena hoje muitas das investigações semióticas com a GDV de Kress e van Leeuwen ([1996], 2001, 2006), fazendo surgir pesquisas com o intuito de suplantar algumas das dificuldades em se analisar sistematicamente estruturas visuais e outros códigos semióticos, posto que, até então, "os paradigmas de investigação dessas estruturas enfocavam exclusivamente o léxico das imagens, ou seja, não iam além da camada denotativa, conotativa e/ou iconográfica de seus níveis de significação” (ALMEIDA, 2011, p. 174).

Diante das inúmeras transformações sociais e educacionais no Brasil, pensar o ensino de leitura e escrita na perspectiva do estudo de gêneros discursivos multimodais nas várias atividades da comunicação multimodal têm requerido de todos/as nós, sobretudo professores/as, uma reflexão acerca da "prática de letramento da escrita, do signo verbal [que] deve ser incorporada à prática de letramento da imagem, do signo visual" (DIONÍSIO, 2005, p. 160).

Por isso, a autora acrescenta que a multimodalidade é um traço constitutivo tanto do discurso oral como do escrito e que a escrita tem oferecido cada vez. mais arranjos não-padrões em razão do desenvolvimento tecnológico e digital em uma sociedade cada vez mais multimodal e globalizada, o que demanda dos/as leitores/as mudanças significativas em seus comportamentos e práticas de leitura e de escrita compartilhados por atividades retóricas em grupos ou instituições em um determinado ordenamento social (BAZERMAN, 2005a).

O fenômeno dos letramentos são vistos, atualmente, tanto de forma individual como um conjunto de habilidades pessoais atrelados a leitura e a escrita, podendo ser percebido esses letramentos na perspectiva social, resultando no que as pessoas podem fazer efetivamente com tais habilidades em contextos específicos e como tais habilidades se relacionam com suas necessidades, valores e práticas sociais, porque são, na verdade, "um 
conjunto de práticas sociais ligadas à leitura e à escrita em que os indivíduos se envolvem em seu contexto social" (SOARES, 2004, p. 72).

Nesse sentido, Lima (2015, p. 4) ao pesquisar a multimodalidade e a leitura crítica em novas perspectivas para o ensino de língua portuguesa acentua que "a relação entre os modos semióticos verbais e não verbais presentes nos textos criaram outras possibilidades de leitura crítica, fazendo surgir a necessidade de uma abordagem multimodal". Esta pesquisadora reforça que

Se a constituição dos textos mudou, a nossa maneira de ler precisa ser revista. O processo de leitura não deveria ser pautado apenas nos fatores verbais. $\mathrm{O}$ ato de ler precisa ampliar e considerar todos os elementos empregados pelo autor na construção do texto. As mudanças ocorridas nos textos geraram a necessidade da realização de novos estudos a respeito dos elementos multissemióticos que estão constituindo a comunicação na sociedade atual (LIMA, 2015, p. 14).

Isso significa dizer que, dentro do contexto de interação sócio-comunicativo em diferentes espaços sociais, muitas das habilidades de leitura são salutares para todos/as estudantes da educação básica, contudo tornou-se especialmente importante para os/as leitores/as em formação, pois eles/as devem adquirir conceitos e conhecimentos iniciais oferecidos em muitos dos conteúdos curriculares ensinados na escola, através de diversos suportes: jornais, livros, internet etc., objetivando o desenvolvimento da capacidade de compreensão com criticidade, de modo a construir de maneira significativa a competência leitora, uma vez que a leitura de textos não pode se reduzir à leitura no e para o contexto escolar, mas deve se expandir nas várias práticas sociais situadas em contextos de comunicação multimodal (PAIVA, 2013; 2016).

Para Kress e van Leeuwen (2006), assim como a língua possui uma gramática que descreve a combinação das palavras em orações, sentença e textos, as imagens possuem um modo, que eles chamam de gramática visual, de combinar pessoas, lugares e coisas, em frases de maior ou menor complexidade com extensões diversas. Em pesquisa de doutoramento, Alves (2016) parte da concepção de que a 
[...] multimodalidade traz consigo algumas exigências conceituais que estão intrinsecamente ligadas à linguística. Por exemplo, a noção de texto não pode mais ser apenas relativa ao texto verbal, composto por palavras, frases e parágrafos. Entendemos do texto como materialização de discurso, independentemente de expressões de linguagem utilizada. $\mathbf{O}$ conceito de multimodalidade aqui apropriado é o exposto por Kress e van Leeuwen (2006), autores que enunciam que os gêneros escritos combinam a língua, a imagem e as características gráficas para significar o texto como um todo. (ALVES, 2016, p. 26, grifos nossos).

Apropriando-se dos pressupostos conceituais acima, pode-se, assim, dizer que a multimodalidade ${ }^{9}$ relaciona-se às mais diversificadas formas, recursos e modos de representação usados na construção linguística de uma determinada mensagem, tais como: palavras, imagens cores, formatos, marcas / traços tipográficos, disposição da grafia, gestos, padrões de entonação, olhares etc. (DIONÍSIO, 2005; 2011; SILVINO, 2012), em consonância da integração multissemiótica de diferentes textos e linguagens, que fazem parte da vida de todos/as na contemporaneidade, por isso a necessidade de estudos sobre esses fenômenos vem se destacando cada vez mais no contexto brasileiro.

\section{Metodologia: a construção e as travessias da pesquisa}

Em um prisma teórico-metodológico, esta pesquisa se situa no campo de estudo da Linguística Aplicada (LA) que tem contribuído na utilização de métodos de investigação de base qualitativo-interpretativista (ERICKSON, 1996; MOITA LOPES, 1994, 1996, 2006). Até porque a LA reveste-se de uma natureza inter e transdisciplinar, colocando-se em função de "[...] criar inteligibilidade sobre problemas sociais em que a linguagem tem um papel central" (MOITA LOPES, 2006, p.14). Na seara dos estudos multimodais e semiótico-sociais na contemporaneidade, Novellino (2011) acentua que as

\footnotetext{
${ }^{9}$ Santos e Pimenta (2014, p. 302) salienta com base nas pesquisas de Cope e Kalantzis que a Multimodalidade se rege pelo princípio de que todos os textos são multimodais, que neles podem prevalecer determinadas modalidades, entretanto jamais terá somente uma. A classificação dos múltiplos modos semióticos (imagem, layout, fonte, cor etc) é o que Kress (2010) designa de fenômeno multimodal.
} 
[d]iversas abordagens multimodais vêm sendo elaboradas nos últimos anos decorrentes sobretudo do interesse de diversos pesquisadores (KRESS, 2009, 2010; NORRIS, 2004, 2009; VAN LEEUWEN, 2005; LEMKE, 2006; BALDRY; THIBAULT, 2006) em relação à a. produção e interpretação do significado pelos indivíduos quando numa interação, b. organização interna de cada modo comunicacional, e c. maneira como se dá a integração e a compressão dos modos nos textos multimodais (NOVELLINO, 2011, p. 75, grifos nossos).

Consoante às referências acima, muitos/as pesquisadores/as, como Kress (2000, 2005, 2009, 2010), van Leeuwen (2004, 2005, 2009), Kress e van Leeuwen ([1996], 2006), Christie (1999, 2007), Baldry e Thibault (2006), Lemke (1989, 1992), Jewitt e Oyama (2004), para citar apenas alguns, que atuam nos campos da educação, linguística aplicada, música, artes e design, desenvolvendo estudos e investigações ligadas à maneira como, por exemplo, textos verbo-visuais e/ou imagéticos se agregam com os textos verbais escritos, orais e multimodais na produção de significados variados na sociedade (NOVELLINO, 2011).

Com base em Van Leeuwen (2005), o trabalho do/a pesquisador/a em Semiótica Social compete - coletar, identificar e catalogar os modos usados na produção de significados em diversos documentos, investigar as condições históricas peculiares de produção e interpretação de significados de determinados artefatos multimodais; e, por fim, identificar outros recursos semióticos, além de novos usos para recursos já existentes (VELOSO, 2014).

A amostra deste estudo foi constituída de oito propostas de redação do Enem, aplicadas ao longo de 2009 a 2016 e de dezesseis redações com nota máxima, escolhidas aleatoriamente em sites especializados e em cinco Guias/Cartilhas (2012 a 2016), retiradas 
desses documentos duas redações-modelo dos participantes, analisadas pela Banca de Avaliadores (UnB/Vunesp) ${ }^{10}$. Ressaltei que as práticas discursivas e as relações dialógicas constituídas a partir da análise de Oliveira (2016, p. 106), em redações do Enem, em seus aspectos externos e internos caracterizam esse texto como um gênero discursivo de caráter predominantemente argumentativo e opinativa (CAVALCANTE, 2016).

\section{Análise multimodal crítica dos textos verbo-visuais e das redações nota máxima do Enem: recontextualizando alguns resultados}

Em uma perspectiva dos estudos multimodais da GDV e da ADC, analiso as categorias e as estratégias de recontextualização em dezesseis redações com nota máxima (redações-modelo), porque ficou comprovado que compreender a recontextualização (BERNSTEIN, 1990; FAIRCLOUGH, 2006; VAN LEEUWEN, 2008), em práticas de letramento no Enem, foi essencial à produção final das redações avaliadas com nota máxima (redações-modelo), já que esses textos seguiram as orientações da Matriz de Competências de Redação do Enem.

É preciso considerar que apenas fazer os/as candidatos/as colocarem os olhos (decodificarem) durante a atividade de leitura de forma perceptivo-visual tão-somente nos limites dos textos/enunciados ainda é pouco, por isso levei em conta a relação funcional depreendida entre linguagem verbal e visual/imagética, multimodal ou, até mesmo, as relações semióticas que compõem os gêneros considerados verbo-visuais. Isso demonstrou a situação enunciativa que é intrínseca ao discurso, envolvendo texto, prática social e prática discursiva (FAIRCLOUGH, 2003), posto que os textos que produzimos - são partes essenciais da forma como atuamos na sociedade - não apenas são resultados das situações sociais corriqueiras em que ocorrem, mas também têm implicações sobre elas (RESENDE, 2017).

\footnotetext{
${ }^{10}$ Vale salientar que até 2016, as avaliações das redações ficaram a cargo de elaboração e avaliação por especialista da Universidade de Brasília. Porém, em 2017 ficou esse processo sob a responsabilidade da Vunesp/Unesp.
} 
Dessa forma, o contexto situado de comunicação, produção, consumo e circulação de textos/gêneros discursivos influenciaram no comportamento dos sujeitos sociais, já que estes têm suas práticas discursivas (FAIRCLOUGH, 2006) moldadas pela anuência a um ordenamento social e retoricamente determinado pelo uso da língua(gem) em múltiplas atividades da vida humana (BAZERMAN, 2005a, 2005b). Sob esta ótica entendi que a recontextualização produz um efeito de apropriação de determinados elementos de práticas sociais em outras, em que determinadas práticas ganham outros sentidos e produzem novas ideologias na vida social (FAIRCLOUGH, 2006; ORMUNDO, 2007).

A seguir, trago a mensuração de quais os textos foram recorrentemente contemplados nas edições (2009 a 2016) do Exame Nacional do Ensino Médio, quanto à elaboração retórico-composicional da prova de redação. A tabela 1 mostrou detalhadamente a distribuição dos textos verbo-visuais analisados, conforme as edições do exame:

Tabela 1 - Distribuição dos textos verbo-visuais nas Propostas de Redação do Enem

\begin{tabular}{|c|c|c|c|c|c|c|c|c|}
\hline \multicolumn{9}{|c|}{ QUANTITATIVO DO CORPUS DE PESQUISA } \\
\hline $\begin{array}{c}\text { Proposta de Redação do } \\
\text { Enem }\end{array}$ & 2009 & 2010 & 2011 & 2012 & 2013 & 2014 & 2015 & 2016 \\
\hline Total de gêneros/textos & 3 & 4 & 3 & 4 & 4 & 3 & 4 & 4 \\
\hline $\begin{array}{c}\text { Textos verbo-visuais } \\
\text { analisados }\end{array}$ & 1 & 2 & 1 & 1 & 2 & 1 & 3 & 1 \\
\hline Percentual $^{11}$ & $34 \%$ & $50 \%$ & $34 \%$ & $25 \%$ & $50 \%$ & $34 \%$ & $75 \%$ & $25 \%$ \\
\hline
\end{tabular}

Total de textos verbo-visuais analisados: $12(41 \%)$

Do total de 29 (textos) que integraram a composição retórico-discursiva das propostas de redação do Enem, aplicadas de 2009 a 2016, observei a incidência de 17 textos (cerca de 59\%), caracterizados apenas pelo modo semiótico verbal tão comum ao longo das edições anteriores. Por outro lado, considerando o "novo Enem" e os atuais arranjos

11 Taxa de percentual aproximada. 
socioculturais de comunicação multimodal e de produção/consumo de textos verbo-visuais em contextos diversos com fins determinados, além do histórico de uma série de ocorrências quanto à cópia de textos verbais e, consequentemente, o surgimento de inúmeros casos de redações anuladas, foi necessário por parte dos especialistas do INEP/MEC, a reformulação do processo de aplicação do exame, bem como a reestruturação da organização composicional das Propostas de Redação aplicadas.

Essa nova reconfiguração multimodal no Exame requereu dos/as participantes o desenvolvimento de práticas de letramento(s) visual(is) crítico(s) em decorrência da necessidade de integrar os vários modos (verbal, não-verbal, visual, multimodal etc.), foi possível obter uma maior compreensão do processo de recontextualização discursiva do tema em argumentos consistentes e integrados entre si, baseado em uma proficiente seleção dos fatos, opiniões e informações fornecidos pelos textos motivadores, objetivando à escrita competente de um gênero de predominância dissertativo-argumentativa e opinativo (CAVALCANTE, 2016).

\subsection{A organização retórico-composicional das propostas de redação do Enem (2009} a 2016): a constituição multimodal dos textos motivadores

O Novo Enem se consolidou pela prova de produção escrita da "Proposta de Redação" por ter sua organização retórico-composicional relativamente estável, constituindo-se, a grosso modo, em três partes: a) Enunciado introdutório que traz a proposta temática, o gênero solicitado e os encaminhamentos gerais para a sua realização; b) textos de apoio (dois a três, sendo que, na maioria das vezes, um deles possui linguagem verbovisual, como tira, charge, anúncio ou infográfico); c) as instruções, informando todos os comandos para a elaboração do texto (FREITAS; LUNA, 2017).

Apreendo, então, que até 2015, o Enem oferecia tais elementos constitutivos na ordem antecedente, entretanto, a partir da edição de 2016, houve uma anástrofe e uma maior organização multimodal nessa organização e tais partes surgiram bem segmentadas por linhas e títulos em caixa alta: inicialmente, as "Instruções para redação”, em seguida, 
os "Textos motivadores" e, finalmente, a "Proposta de redação", ou seja, o enunciado introdutório mencionado (BRASIL, 2016, p. 2). Tendo em vista às concepções teóricas da multimodalidade, na Semiótica Social de Kress e van Leeuwen (2006) e van Leeuwen (2008), reforço que esses foram os elementos semiótico-composicionais recorrentes na construção da significação das propostas de redação como gêneros discursivos de natureza híbrida ${ }^{12}$, multimodal e intergenérica (PAIVA; LIMA, 2018).

Analisando a composição multimodal das propostas de redação, percebi que a cada edição (2009 a 2016) houve uma maior diversidade de escolha dos gêneros e suportes na distribuição dos textos motivadores que constituíram a estrutura retórico-composicional das propostas de redação do Enem, porque forma esses textos oferecidos como estímulo ao desenvolvimento da temática estando articulados ou desarticulados na construção de intertextos das propostas de redação para um mesmo ponto de vista, para uma mesma orientação discursiva de produção textual. Em relação a verbo-visualidade ${ }^{13}$, observei as ocorrências na organização retórico-composicional das propostas a seguir:

\footnotetext{
12 Segundo Bessa e Sato (2018, p. 138) “"a]s mudanças em cadeias de gêneros [...] demonstram o hibridismo recorrente em diversos gêneros dentro de práticas sociais na modernidade recente (Giddens, 1991; Chouliaraki; Fairclough, 1999; Fairclough, 2003)". (Grifos dos autores).

${ }^{13}$ Brait (2013, p. 51) explica que a verbo-visualidade pode ser entendida como fenômeno em que: “[...] o verbal e o visual casados, articulados num único enunciado, o que pode acontecer na arte ou fora dela, e que tem gradações, pendendo mais para o verbal ou mais para o visual, mas organizados num único plano de expressão, numa combinatória de materialidades, numa expressão material estruturada [...]".
} 
Figura 1 - Tema de redação Enem 2009

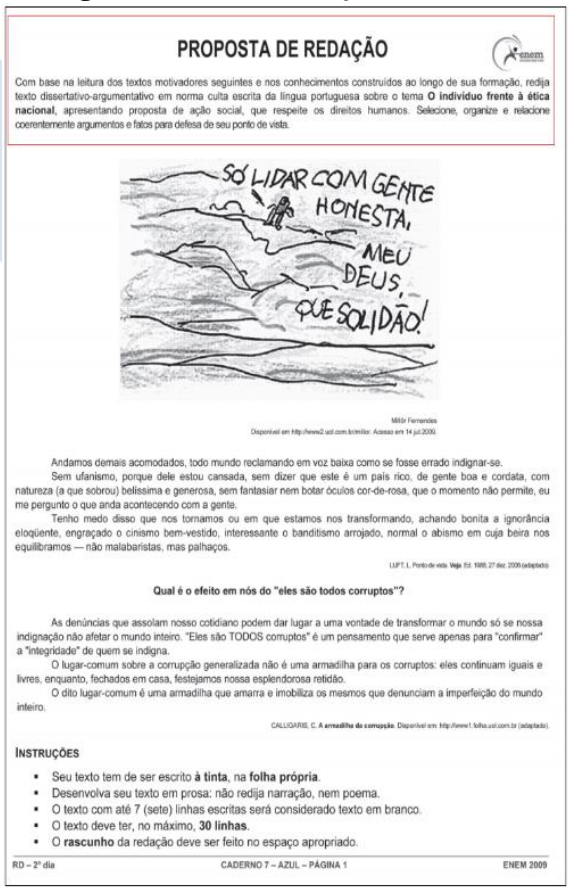

Fonte: Arquivo pessoal
Figura 2 - Tema de redação Enem 2016

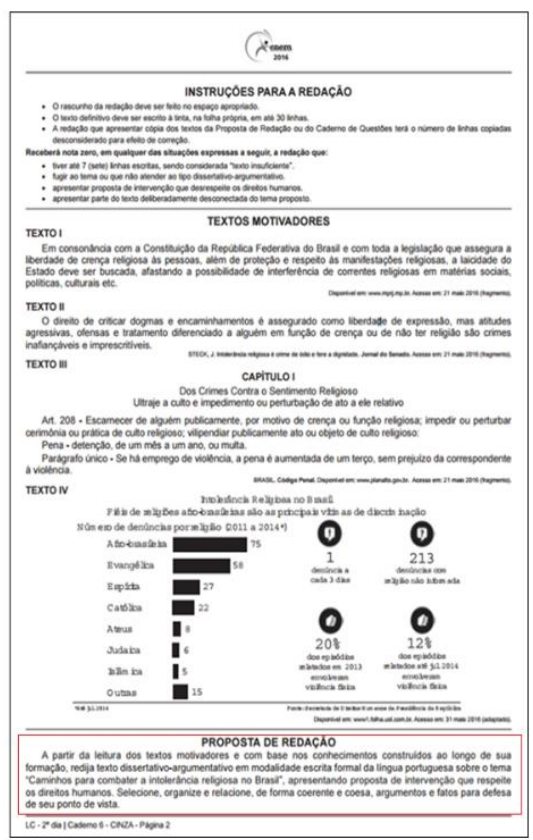

Fonte: Arquivo pessoal

Notei verbo-visualmente que as propostas de redação foram organizadas estruturalmente de forma semelhante, porque foram configuradas sociossemioticamente em razão das necessidades e das práticas sociais/discursivas dos sujeitos - como foi possível verificar, a princípio, no design composicional dos enunciados introdutórios das propostas de 2009 a 2016. 


\subsection{As estratégias de recontextualização como prática discursiva na perspectiva teó- rico-metodológica dos estudos da Semiótica e da Análise de Discurso Critica}

O fenômeno de recontextualização discursiva abrangeu adequações e escolhas de elementos mais relacionados para assentada prática que os agentes procuram representar. Van Leeuwen (2008) distingue os seguintes elementos, que podem ser analisados na recontextualização de uma forma geral: substituição, anulação, rearranjamento e adição (TEIXEIRA, 2013, p. 16). Em suma, os procedimentos discursivos de adição, enredados no processo de recontextualização, e, sobretudo do rearranjo ${ }^{14}$, um procedimento destacado, apenas, em Van Leeuwen (2003) demonstraram como os discursos, textos, gêneros puderam ser multimodalmente (re)arranjados em práticas sociais diversificadas e vinculadas aos propósitos específicos de comunicação multimodal na dita sociedade da imagem (KRESS; VAN LEEUWEN, 2001).

No contexto sociossemioticamente situado de produção escrita e de leitura no Exame Nacional do Ensino Médio, os gêneros discursivos também passaram por transformações, adaptações e rearranjos no processo de recontextualização discursiva dos textos verbo-visuais (multimodais) na construção retórico-composicional das propostas de redação do Enem (2009 a 2016), precisamente por estarem submersos em práticas sociais e fazerem as multissemioses entre estas e os textos motivadores, sobretudo da esfera de língua(gem) jornalística, didática e da área jurídico-institucional, isso trouxe a significação de que "um gênero implica não somente um tipo particular de texto, mas também processos particulares de produção, distribuição e consumo de textos” (FAIRCLOUGH, 2001, p. 161).

No quadro, a seguir, com base no estudo de Van Leeuwen (2008) e de outros/as pesquisadores/as, categorizei as principais estratégias de recontextualização:

\footnotetext{
14 Metodologicamente, optei em analisar apenas essas duas categorias da recontextualização (adição e rearranjo) devido à análise-piloto, feita por Paiva e Lima (2018) que evidenciou estes estarem mais associados à construção da competência III que avalia se o/a candidato/a foi capaz de (selecionar, relacionar, organizar e interpretar informações, fatos, opiniões e argumentos em defesa de um ponto de vista).
} 
Quadro 2 - Categorização das estratégias de recontextualização em redações-modelo

\begin{tabular}{|c|c|c|}
\hline $\begin{array}{l}\text { SIGNIFICADOS DA } \\
\text { RECONTEX- } \\
\text { TUALIZAÇÃO }\end{array}$ & $\begin{array}{c}\text { CARACTERÍSTICA } \\
\text { S DAS } \\
\text { ESTRATÉGIAS } \\
\text { APLICADAS }\end{array}$ & $\begin{array}{l}\text { OCORRÊNCIAS NAS } \\
\text { REDAÇÕES-MODELO }\end{array}$ \\
\hline $\begin{array}{l}\text { - O processo de recontextualização } \\
\text { em práticas de letramento } \\
\text { em leitura e escrita no Enem } \\
\text { é um conceito relevante para } \\
\text { entendermos a produção fi- } \\
\text { nal das redações avaliadas } \\
\text { com nota máxima (redações- } \\
\text { modelo), seguindo o rigor } \\
\text { das orientações da matriz de } \\
\text { competências de redação do } \\
\text { Enem, além de tornar evi- } \\
\text { dente as estratégias de re- } \\
\text { contextualização adotadas } \\
\text { pelos/as candidatos/as do } \\
\text { exame quando necessitam } \\
\text { acionar práticas de letramen- } \\
\text { tos visual crítico para com- } \\
\text { preender os muitos textos } \\
\text { (gêneros) produzidos e situ- } \\
\text { ados das muitas esferas da } \\
\text { língua(gem) e da comunica- } \\
\text { ção, sobretudo da esfera: } \\
\text { jornalística, publicitária, di- } \\
\text { dática, oficial, entre outros } \\
\text { - A ação retórica e estratégica } \\
\text { de recontextualização incidiu } \\
\text { fundamentalmente na articu- } \\
\text { lação/integração de textos e } \\
\text { de práticas de um contexto } \\
\text { primário de produção dis- } \\
\text { cursiva para um contexto se- } \\
\text { cundário de reprodução dis- } \\
\text { cursiva, como defende Ber- } \\
\text { nstein (1990) são, de certa } \\
\text { forma, "regidos por princí- } \\
\text { pios recontextualizadores } \\
\text { que, de forma seletiva, se }\end{array}$ & $\begin{array}{l}\text { 1. Rearranjo - tratou } \\
\text { da própria disposição } \\
\text { do texto, a ordem de } \\
\text { importância das infor- } \\
\text { mações que foram re- } \\
\text { contextualizadas para } \\
\text { atingir determinadas } \\
\text { funções, como, inclu- } \\
\text { sive, argumentar/per- } \\
\text { suadir/convencer. }\end{array}$ & $\begin{array}{l}\checkmark \text { Além disso, a mobilização deve } \\
\text { agir na direção de quem mais ne- } \\
\text { cessita, ajudando, educando e } \\
\text { oferecendo oportunidades para } \\
\text { excluídos, que vivem à mar- } \\
\text { gem da vida social, abaixo da } \\
\text { linha da humanidade" [3]. } \\
\text { (Trecho da redação } 2 \text { de } 2009 \text { ). } \\
\checkmark \text { "No Brasil, a lei Áurea foi assi- } \\
\text { nada em } 1888 \text { [1], porém são } \\
\text { vários os casos em que proprie- } \\
\text { tários de terras se aproveitam } \\
\text { da situação financeira precá- } \\
\text { ria do indivíduo para explorá- } \\
\text { lo, pagando-lhe um salário me- } \\
\text { díocre." (Trecho da redação } 1 \\
\text { de } 2010 \text { ). } \\
\text { "Por isso, diversas empresas e } \\
\text { personalidades se valem da } \\
\text { criação de perfis próprios [2], } \\
\text { atraindo diversos seguidores, aos } \\
\text { quais impõe sua maneira de agir } \\
\text { e pensar". (Trecho da redação } 1 \\
\text { de } 2011 \text { ). } \\
\text { "Como mostra o passado, os } \\
\text { imigrantes podem favorecer o } \\
\text { desenvolvimento e o futuro } \\
\text { promete ainda mais pessoas } \\
\text { vindo para o Brasil" [5]. (Tre- } \\
\text { cho da redação } 2 \text { de } 2012 \text { ). } \\
\text { "As estatísticas explicitam a } \\
\text { queda brusca na ocorrência de } \\
\text { óbitos decorrentes de aciden- } \\
\text { tes de trânsito depois da en- } \\
\text { trada da Lei Seca em vigor" } \\
\text { 2013). }\end{array}$ \\
\hline
\end{tabular}


apropriam, reorganizam, alteram o foco e se relacionam com outros discursos para constituir sua própria ordem e ordenamentos" (BERNSTEIN, 1990, p. 184).

- Van Leeuwen (2008) explicita que essa circulação de textos se acondiciona graças aos agentes/consumidores/produtores que, por sua vez, estão inseridos em específicas práticas sociais. Dessa forma, a prática recontextualizadora (por ex., as estratégias usadas pelos/as participantes ao lerem os textos verbo-visuais das propostas de redação que norteiam a prática de leitura visual e escrita textual), de fato, é articulada por uma sequência de atividades linguísticas e/ou semióticas, isto é, trata-se sempre de um ou mais gêneros, textos, discursos que muitas vezes partem de uma cadeia, sistema de gêneros ou domínio discursivo, fazendo com que as práticas sociais são recontextualizadas, ressignificadas e postas em circulação social.

- O fenômeno de recontextualização ocorre no Exame Nacional do Ensino Médio, evento em que os participantes são instados a escreverem, tendo em vista o contexto social, político, econômico etc., que estão integrados, tendo ainda suas práticas discursivas moldadas a partir do que é requerido no exame em conformi-

Em abril de 2014, foi aprovada uma resolução que julga abusiva essa publicidade infantil, gerando conflitos entre as empresas, organizações publicitárias e os defensores dos direitos deste público-alvo" [2]. (Trecho da redação 1 de 2014).

"De acordo com o Mapa da Violência de 2012, entre 1980 e 2010 houve um aumento de $230 \%$ na quantidade de mulheres vítimas de assassinato no país" [1]. (Trecho da redação 2 de 2015).

$\checkmark$ "No entanto, não é razoável que ainda haja uma religião que subjugue as outras, o que deve, pois, ser repudiado em um Estado laico, a fim de que se combata a intolerância de crença". [3]. (Trecho da redação 1 de 2016).

\section{Adição - definiu} como informações adicionais que foram incorporadas nas práticas que passaram pela recontextualização. A adição realizou- se por meio de mecanismos como legitimação, em que se utilizou da fala/discurso de autoridades que se consolidou prática social específica; e avaliação, quando, a partir de julgamentos, ações foram qualificadas.
"[...] isso faz com que seja necessária a criação de corporações militares - como é o caso das UPPs na cidade do Rio de Janeiro [2], que buscam pacificar as regiões das favelas da cidade através do combate ao tráfico de drogas - ou leis que buscam amenizar crimes". (Trecho da redação 1 de 2009).

"Além disso, a mídia deveria procurar casos em que o trabalhador é explorado e noticiá-los, para que, assim, a população se sensibilize e procure denunciar, aos órgãos governamentais locais, esse tipo de situação degradante" [4]. (Trecho da redação 1 de 2010).

$\checkmark$ "Crimes virtuais, processos jurídicos, disseminação de 
dade da proposta a ser produzida (PAIVA; LIMA, 2018). ideias, organização de manifestações são apenas alguns exemplos da integração que se faz entre o real e o virtual" [5]. (Trecho da redação 2 de 2011).

$\checkmark \quad$ "Um dos grandes responsáveis por esse cenário é o papel de liderança e representatividade que o Brasil assume em órgãos como o Mercosul, o FMI e a ONU" [3]. (Trecho da redação 1 de 2012).

$\checkmark \quad$ "Por ter penalizações reais e duras, a lei trouxe resultados visíveis, beneficiando o sistema de saúde (pela diminuição nos índices de vítimas de acidentes) e a segurança no trânsito (pelo menor número de alcoolizados no volante)" [4]. (Trecho da redação 2 de 2013).

$\checkmark \quad$ "De acordo com o sociólogo Émile Durkheim, é na infância que os indivíduos passam pelo processo de socialização, ou seja, adquirem os valores morais e éticos da sociedade em que se encontram" [1]. (Trecho da redação 2 de 2014).

$\checkmark \quad$ "Nesse âmbito, pode-se analisar que essa problemática persiste por ter raízes históricas e ideológicas" [4]. (Trecho da redação 1 de 2015).

$\checkmark \quad$ "Em primeiro plano, é necessário que a sociedade não seja uma reprodução da casa colonial, como disserta Gilberto Freyre em "Casa-grande e Senzala" [1]. (Trecho da redação 1 de 2016). 
Nesta pesquisa, busquei aplicar os elementos de recontextualização mais perceptíveis na argumentação persuasiva e na constituição composicional das propostas de redação do Enem (c.f. PAIVA; LIMA, 2018), entre eles, os de rearranjo e adição em consonância com à Competência III da Matriz de Redação do Enem. Tal questão teóricometodológica foi maiormente estudada, em Van Leeuwen (2008) que explicitou que essa circulação de textos se condiciona por agentes/consumidores(as)/produtores(as) que, por sua vez, estão inseridos em específicas práticas sociais ${ }^{15}$.

Dessa forma, compreendi que a prática de recontextualização se materializou em estratégias, entre as quais: verbo-visualizar as informações das imagens e de seus elementos socioculturais; compreender a inter-relação entre o texto verbal e visual ou verbo-visual e seus elementos socioculturais; desenvolver a consciência crítica e emancipativa dos/as leitores/as sobre o potencial semiótico de um texto; interpretar os valores informativos, saliência e enquadramento [framing] de um texto imagético; refletir sobre o contexto bistórico em que um texto verbo-visual foram culturalmente situado; analisar os recursos semióticos usados para prender a atenção dos leitores/as, negrito, fonte, modulação e saturação de cores, uso de icones, simbolos e sinais, disposição das informações etc.

Em relação aos temas de 2009 a 2011, verifiquei que os meios de circulação da mídia impressa e digital foram as fundamentais fontes dos textos que constituem à estrutura híbrida e de intergenericidade das propostas de redação, pois possuem em sua constituição composicional informações diversas sobre tecnologia, ciência, saúde, comportamento e informática que foram recontextualizadas em arranjos semióticos de significados sociais, construídos pelos argumentos, contra-argumentos e encaminhamentos de intervenção(ções) de cada participante.

Já as propostas das edições de 2012 e 2013, se destacaram pela natureza discursiva oficial/institucional presente nos textos que apoiam e direcionaram a produção da redação, porque a maior parte das fontes usadas para subsidiar este tema foram extraídas

\footnotetext{
${ }^{15}$ Fairclough (2003) assinala que as práticas sociais podem ser compreendidas como formas de controlar a seleção de certas possibilidades estruturais e excluir outras em determinadas situações particulares. Dessa maneira, as práticas são responsáveis por articular as estruturas sociais (linguagem) e os eventos sociais (textos).
} 
do campo ideológico institucional e das relações de poder, provindas dos setores do Governo ou que estiveram ligadas a ele, nada mais comum o surgimento de argumentos, corroborando com os discursos legalistas do Estado, além ter havido na tessitura dos excertos de redações-modelo, muitas contra-argumentações, objetivando refutar ideias e fatos, propondo outras intervenções mais viáveis e concretas. Por fim, ao considerar os muitos problemas sociais postos diante dos/as leitores/as surgiu também a necessidade de verbovisualizar os significados dos textos motivadores que ajudaram bastante na elaboração de uma argumentação persuasiva consistente e produtiva no Enem.

No que se referiu as propostas de 2014 e de 2015, consegui perceber a tentativa de convergência ideológica dos textos motivadores, das práticas sociais e discursivas dos/as candidatos/as ao se utilizarem de estratégias de recontextualização para construção de uma argumentação persuasiva condizente com os ditames da CIII concernentes a Matriz de "Correção" de Redação do Enem.

Ademais, os textos verbais e o gênero multimodal infográfico que constituíram a proposta de 2016, foram integrados no sentido de oferecer aos candidatos/as informações concretas, dados estatísticos, fatos etc., que puderam ser materializados em forma de argumentos, reproduzindo os vários discursos institucionalizados dos órgãos de Governo, da esfera jornalística e acadêmica no combate à intolerância religiosa, porque muitos dos argumentos resultaram de recontextualização, rearranjo e adição (VAN LEEUWEN, 2008), a partir da leitura e compreensão multimodais dos textos verbo-visuais que estiveram visíveis nos excertos das redações-modelo analisadas, especialmente quanto as religiões de matriz africana que foram os maiores alvos da intolerância religiosa no Brasil, seguida pelas religiões evangélicas e pelo Espiritismo.

Percebi, então, que existia uma atenção particular do órgão responsável pelo Enem, o INEP, tanto no design composicional das propostas de redação (2009 a 2016) quanto na escolha dos temas, argumentos, posicionamentos ideológicos e pelo próprio direcionamento social dado as propostas de intervenção(ões) requeridas na produção desse texto/gênero de caráter predominantemente dissertativo-argumentativo e opinativo, ou 
seja, tal processo de mudança social no Enem, se fez como uma construção dialética, híbrida e multimodal em que a relação entre a linguagem, o processo de globalização (FAIRCLOUGH, 2006) e as atividades sociais perpassaram as denominadas vozes da globalização, abalizadas em cinco principais agências: a análise acadêmica, as agências governamentais, as agências não-governamentais, a mídia e as pessoas na vida social.

Em contrapartida, a análise semiótico-visual de redações-modelo de 2009 a 2016 revelou uma relação intertextual, intergenérica e integrativa entre os modos verbais e imagéticos, resultando em efeitos discursivos e em "novas" relações semióticas presentes na formulação dos argumentos, construídos pelos/as candidatos/as do exame. Notei ainda uma maior organização da composição das propostas com a presença de mais textos verbo-visuais, ao longo das edições, para facilitar o acesso e apreensão dos dados, informações, opiniões e fatos que auxiliaram na progressão de ideias e do tema, na posição autoral de cada um/a, na elaboração de intervenções plausíveis e concernentes a um dado problema social, aspectos essenciais durante o planejamento à escrita final do texto de caráter dissertativo-argumentativo e opinativo.

Considerando às condições de produção, circulação e consumos de textos, compreendi, portanto, a intergenericidade ou intertextualidade intergenérica como recurso necessário à construção composição multimodal de sentidos, pois as propostas de redação se configuraram de forma híbrida (MARCUSCHI, 2002), caracterizando-se pelas relações de intergenericidade que se evidenciaram quando um gênero "exerce a função de outro, o que revela a possibilidade de operação e maleabilidade que dá aos gêneros enorme capacidade de adaptação e ausência de rigidez" (KOCH, BENTES; CAVALCANTE, 2007, p. 31).

Finalmente, a análise e as experiências de letramento visual crítico empreendidas neste estudo, possibilitou avaliar às estratégias adotadas pelos/as participantes na seleção e organização dos argumentos encontrados em excertos de redações-modelo, que, na maioria das vezes, foram recontextualizados, especialmente, em forma de rearranjo e adição, a partir da leitura crítica e da verbo-visualidade dos textos verbo-visuais das propostas de redação (2009 a 2016), pois apresentaram uma abundância de informações, gêneros discursivos e 
elementos verbais e visuais integrados a essas mesmas propostas. Assim, pude perceber a materialidade discursiva de articulação nas redações-modelo, a partir do uso das estratégias de: exemplificação, alusão histórica e discursos de autoridade na construção da argumentatividade na Competência III da Matriz de Redação do Enem.

Logo, com base nas análises realizadas, constatei que houve ao longo das edições do Enem (2009-2016), uma exploração analítica e produtiva não apenas dos textos verbais, mas, em especial, dos verbo-visuais e/ou imagéticos, de modo que estes contribuíram sobremaneira dando maior informatividade, inteligibilidade, coerência e plausibilidade entre as ideias apresentadas, potencializando, consequentemente o poder semiótico da argumentação persuasiva dos/as participantes que buscaram conjugar mais os textos verbais (cerca de 17 textos verbais, correspondendo a 59\%) aos textos verbo-visuais, constituindo, portanto, um todo de significação multimodal (KRESS; VAN LEEUWEN, 1996), a partir da análise semiótico-visual dessas propostas de redação.

\section{Considerações finais}

Para chegar a resultados efetivos, adotei ao longo deste estudo, uma abordagem sociossemiótica, pautada em estudos multimodais visuais críticos da Semiótica Social (HODGE; KRESS, 1988; VAN LEEUWEN, 2005; KRESS, 2010); e da Análise de Discurso Crítica (FAIRCLOUGH, 2001, 2003, 2006), apenas para citar alguns, porque acredito que “o acesso às habilidades visuais, amplia as possibilidades pedagógicas e promove o desenvolvimento da capacidade crítica dos aprendizes no sentido de exercitar a reflexão sobre o construto ideológico erguido por trás da composição de estruturas semióticas visuais" (ALMEIDA, 2011, p. 177).

A análise dos dados e os resultados comprovaram que a composição multimodal das propostas de redação no Enem (2009 a 2016), estruturaram-se de forma relativamente estável (BAKHTIN, [1997] 2003) ao longo dessas edições, porque demandou dos/as participantes uma análise visual crítica das informações/fatos, opiniões para o desenvolvimento de argumentos produtivos, geralmente, recontextualizados a partir dos textos verbo- 
visuais, caracterizados pela integração dos elementos semióticos que se organizaram nos textos verbo-visuais alimentados pelas práticas discursivas/sociais de língua(gem) e de produção semiótica de significados composicionais integrados.

Verifiquei, então, que as estratégias de recontextualização em forma de rearranjo e adição foram determinantes para a construção multimodal da argumentação e dos significados sociais compartilhados pelos agentes/produtores/as de textos no Enem. Porque tanto havia a necessidade de entender o propósito de comunicação no design e nos enunciados verbo-visuais da constituição multimodal das propostas de redação do Enem, como se teve a necessidade de elaborar: teses, argumentos, contra-argumentos, posicionamentos ideológicos para compreender o próprio direcionamento social dado às intervenções requeridas pelo exame aos participantes na produção desse gênero de caráter predominantemente dissertativo-argumentativo e opinativo.

A categorização e a análise das estratégias de recontextualizações operadas por participantes do Enem, em um corpus de redações-modelo, contribuíram para demonstrar a capacidade de verbo-visualidade na recontextualização (VAN LEEUWEN, 2008) das informações/dados presentes na composição multimodal dessas propostas. De fato, esse fator foi essencial na construção da argumentatividade, dando inteligibilidade ao texto, além de ajudar na construção da coerência e plausibilidade entre as ideias apresentadas no projeto de texto final à banca examinadora.

Por fim, a análise multimodal empreendida tanto nas propostas de redação (2009 a 2016) quanto nas redações-modelo escritas, a partir dessas mesmas propostas, possibilitou notar o "poder semiótico" (KRESS, 2003) de escrita e leitura que esses participantes utilizaram quando recontextualizaram os discursos, informações, fatos e conhecimentos presentes na maioria dos textos verbo-visuais que compõem as propostas de redação do Enem, muitos dos quais, foram retirados, especialmente, da esfera jornalística e publicitária, objetivando, a meu ver, contribuir na construção de uma argumentação consistente, produtiva e persuasiva, favorecendo, assim, a elaboração de propostas de intervenção(ões) a situação-problema que pudessem satisfazer os critérios avaliativos da banca examinadora. 


\title{
VERB-VISUAL CONFIGURATION AND RECONTEXTUALIZATION STRATEGIES IN ESSAY PROPOSALS OF ENEM
}

\begin{abstract}
This research investigated the process of verbal-visual texts recontextualization in model essays through the analyses of multimodal composition of the Enem essay proposals. These proposals have focused on basic skills that are stimulated and transformed by practices of critical visual literacy (read, see, visualize, think, interpret and communicate) that are required to produce two multiple social meanings through the verb visuality of texts available in these proposals. This research is based on Multimodality, Visual Literacy, Social Semiotics (HODGE and KRESS, 1988; KRESS and VAN LEEUWEN, [1996] 2006; KRESS, 2003, 2010), some categories of analysis - text, social practice and discursive practice, and on Critical Discourse Analysis (FAIRCLOUGH, 2001, 2003, 2006), contributing to the analysis and categorization of discursive recontextualization strategies (VAN LEEUWEN, 2008; TEIXEIRA, 2013) in a corpus of model essays in the light of the theoretical-methodological frameworks listed. The data analysis and the results have shown that the multimodal composition of writing proposals (2009 to 2016) is relatively stable, because they demand from the participants a critical visual analysis of the information / facts and opinions for the development of productive arguments that are usually recontextualized by rearrangement and addition (VAN LEEUWEN, 2008), characterized by the integration of semiotic elements that are organized and nourished by the discursive / social practices of language and semiotic production of integrated meanings.
\end{abstract}

KEYWORDS: Critical Multimodal Analysis. Recontextualization. Essay Proposals of Enem. ModelEssays.

\section{REFERÊNCIAS}

ALMEIDA, D. B. L. Pelos caminhos do letramento visual: por uma proposta multimodal de leitura crítica de imagens. In: ARAÚJO, A. D. (org). Linguagem em Foco. Revista do Programa de Pós-graduação em Linguística Aplicada da UECE, 2011, p. 53-63. Disponível em: <http://www.uece.br/linguagememfoco/dmdocuments/Linguagem $\% 20 \mathrm{em} \% 20 \mathrm{Foco}$ \%202011_2.pdf>. Acesso em 02 jan. 2017.

. Do texto às imagens: as novas fronteiras do letramento visual. In: PEREIRA, R. C.; ROCA, P. (orgs.) Linguística Aplicada - um caminho com diferentes acessos. São Paulo: Editora Contexto, 2011, p. 173-202.

ALVES, R. B. Multimodalidade no livro didático sob as perspectivas da análise do discurso e da retórica contemporânea. 2016. 200f. Tese (doutorado em Letras e Linguística), Programa de Pós-graduação da Faculdade de Letras da Universidade Federal de Goiás, Goiás, 2016.

BAKHTIN, M. Estética da criação verbal. 2. ed. (Trad. Maria Ermantina Pereira). São Paulo: Martins Fontes, 1997.

BALDRY, A.; THIBAULT, P. J. Multimodal transcription and text analysis. London: Equinox Publishing Ltda., 2006. 
BAZERMAN, C. Teoria da ação letrada. São Paulo: Parábola, 2015a.

. Retórica da ação letrada. (Trad. Adail Sobral, Angela Dionisio, Judith Chambliss Hoffnagel, Pietra Acunha). São Paulo: Parábola Editorial, 2015b.

BERNSTEIN, B. The structuring of pedagogic discourse. Londres: Routledge, 1990. Disponível em: <https://www.taylorfrancis.com/books/9781134413461>. Acesso em: 20 out. 2018.

BESSA, D.; SATO, D. T. B. Categorias de análise. In: BATISTA JUNIOR, J. R. L. et al. (org.). Análise de discurso crítica para linguistas e não linguistas. 1 ed. São Paulo: Parábola, 2018, pp. 124-157.

BUZATO, M. E. K. (org.). Cultura Digital e Linguística Aplicada: Travessias em linguagem, tecnologia e sociedade. Campinas/São Paulo: Pontes Editores, 2016.

BRAIT, B. Olhar e ler: verbo-visualidade em perspectiva dialógica. Bakhtiniana: Revista de Estudos do Discurso, v. 8, p. 43-66, 2013. Disponível em: <https://revistas.pucsp.br/index.php/bakhtiniana/article/view/16568>. Acesso em: 25 nov. 2018.

BRASIL. Ministério da Educação/INEP. Portaria Ministerial nº 438 de 28 de maio de 1998. Brasília: INEP, 1998. Disponível em: http://www.crmariocovas.sp.gov.br/pdf/diretrizes_p0178-0181_c.pdf. Acesso em: 13 mai. 2018.

BRASIL. Lei 9.394, de 20 de dezembro de 1996. Estabelece as diretrizes e bases da educação nacional. 1966. Disponível em: <http://www.planalto.gov.br/ccivil_03/leis/19394.htm>. Acesso em: 13 mai. 2018.

Secretaria de Educação Fundamental. Parâmetros curriculares nacionais: língua portuguesa / Secretaria de Educação Fundamental. 1997 - 16 Brasília: 144p. Disponível em: <http://portal.mec.gov.br/par/195-secretarias112877938/seb-educacao-basica20070 48997/12640-parametros-curricularesnacionais-1o-a-4o-series $>$. Acesso em: 01 set. 2018.

- Parâmetros Curriculares Nacionais do Ensino Médio. Parte II - Linguagens, Códigos e suas Tecnologias. 2000. Disponível em: <http://portal.mec.gov.br/seb/arquivos/pdf/14_24.pdf>. Acesso em: 05 mar. 2018.

. Matriz de Referência Enem 2012. Disponível em: < http://download.inep.gov. br/educacao_basica/Enem/downloads/2012/matriz_referencia_Enem.pdf $>$. Acesso em: 13 mai. 2018.

- A redação no Enem 2013: guia do participante. Disponível em: < http:/ / download.inep.gov.br/educacao_basica/Enem/guia_participante/2013/guia_participante_redacao_Enem_2013.pdf>. Acesso em 10 mar. 2018.

. Exame Nacional do Ensino Médio (Enem). A redação no Enem 2016: Guia do Participante. Brasília, INEP/MEC, 2016. Disponível em: < https://www.Enem.vestibulandoweb.com.br/manual-de-redacao-do-Enem-2016.pdf>. Acesso em: 13 jan. 2018. 
. Redação no Enem 2017 - cartilha do participante. Disponível em:

$<$ http://download.inep.gov.br/educacao_basica/Enem/guia_participante/2017/manual_de_redacao_do_Enem_2017.pdf>. Acesso em: 15 mar. 2018.

Ministério da Educação. Portaria n. 468, de 03 de abril de 2017. 2017. Disponível em: < http://www.lex.com.br/legis_27370339_PORTARIA_N_468_DE_3_DE_ABRIL_DE_2017.aspx>. Acesso em: 27 abr. 2018.

CARVALHO, R. P. de. Metodologia de correção da Redação do Enem. In: BRASIL. Ministério da Educação. Instituto Nacional de Estudos e Pesquisas Educacionais Anísio Teixeira. Exame Nacional do Ensino Médio [Enem]: fundamentação teórico-metodológica. Instituto Nacional de Estudos e Pesquisas Educacionais Anísio Teixeira. Brasília: INEP, 2005. p. 113-117.

CAVALCANTE, M. M. A argumentação persuasiva. In: GARCEZ, L. H. do C.; CORRÊA, V. R. Textos dissertativo-argumentativos: subsídios para qualificação de avaliadores. Brasília: Instituto Nacional de Estudos e Pesquisas Educacionais Anísio Teixeira, 2016, pp. 129-134.

CELLARD, A. A análise documental. In: POUPART, J. et al. A pesquisa qualitativa: enfoques epistemológicos e metodológicos. Petrópolis, Vozes, 2008.

COSCARELLI, C. V. (Org.). Tecnologias para aprender. 1. ed. São Paulo: Parábola Editorial, 2016.

COSTA, F. K. B. DA. Os conceitos de habilidades e competências subjacentes ao Enem e o livro didático do $1^{\circ}$ ano do ensino médio: um estudo comparativo. 2013. 134f. Dissertação (Mestrado em Ensino de Ciências e Matemática), Pós-Graduação em Ensino de Ciências e Matemática, da Universidade Federal do Ceará, 2013.

CHRISTIE, F. Genres and Institutions: Functional Perspectives on Educational Discourse. Encyclopedia of language and education, 2007.

Genre theory and ESL teaching: a systemic functional perspective. TESOL Quaterly, 23, 4, 1999.

DENZIN, N. K.; LINCOLN, Y. A disciplina e a prática da pesquisa qualitativa. In: . (Orgs). Planejamento da pesquisa qualitativa: teorias e abordagens. 2. ed. Porto Alegre: ARTMED, 2006.

DIONÍSIO, A. P. Gêneros multimodais e multiletramento. In: KARWOSKI, A. M. GAYDECZKA, B. BRITO, K.S. (org.) Gêneros textuais: Reflexões e Ensino. Palmas e União da Vitória: Kaygangue, 2005.

Gêneros textuais e multimodalidade. In: KARWOSKI, A. M.; GAYDECZKA, B.; BRITO, K. S. Gêneros textuais: reflexões e ensino. 4. ed. São Paulo: Parábola Editorial, 2011, p. 139. 
ERICKSON, F. Ethnographic Microanalysis. In: Mckay, S. L.; Hornberger (Eds.). Sociolinguistics and language teaching. Cambridge: Cambridge University Press, 1996.

FAIRCLOUGH, N. Discurso e mudança social. Trad. de Izabel Magalhães. Brasília: Editora Universidade de Brasília, [1992] 2001. . Analysing discourse: textual analysis for social research. London: Routledge,

2003. . Language and globalization. London: Routledge, 2006.

FREITAS, L. P. de.; LUNA, T. S. Concepções de texto e escrita nas propostas de produção textual do novo Enem. In: MARCUSCHI, B.; LUNA, T. S. E. Avaliação de língua portuguesa no novo Enem [recurso eletrônico]. Jundiaí: UniAnchieta, 2017. p. 243-280.

HODGE, R.; KRESS, G. Social Semiotics. London: Polity Press, 1988.

JEWITT, C.; OYAMA, R. Visual meaning: a social semiotic approach. In: VAN LEEUWEN, T.; JEWITT, C. (Eds.). Handbook of visual analysis. London: SAGE Publications Ltd., 2004.

KOCH, I. G. V.; BENTES, A. C.; CAVALCANTE, M. M. Intertextualidade: diálogos possíveis. São Paulo: Cortez, 2007.

KRESS, G. R. Multimodality. In: COPE, B.; KALANTZIS, M. (Eds.). Multiliteracies: Literacy Learning and the Design of Social Futures. London, Routlege. 2000. . Literacy in the new media age. London: Routledge, [2003], 2005.

. What is a mode? In: JEWITT, C. (Ed.). The routledge handbook of multimodal analysis. London: Routledge, 2009.

Multimodality: a social semiotic approach to contemporary communication.

London: Routledge, 2010.

KRESS, G.; LEITE-GARCÍA, R.; VAN LEEUWEN, T. Semiótica discursiva. In: VAN DIJK, T.A. (org.). El discurso como estructura y proceso. Estudios del discurso: introduction multidisciplinaria. Vol. 1. Barcelona: Gedisa editorial, 2000, p. 373-416.

KRESS, G.; VAN LEEUWEN, T. Reading Images: The Grammar of Visual Design. London: Routledge, [1996] 2006.

. Multimodal discourse: The Modes and Media of Contemporary Communication. London: Arnold, 2001.

LEMKE, J. L. Interpersonal meaning in Discourse: value orientations. In: DAVIES, M.; RAVELLI, L. (Eds.). Advances in Systemic Linguistics: Recent Theory and Practice. London: Pinter, 1992. 
. Social semiotics: a new model for literacy education. In: BLOOME, D. (Ed.). Classrooms and Literacy, p. 289-309. Norwood, NJ: Ablex Publishing, 1989.

LIMA, E. A. de. Multimodalidade e leitura crítica: novas perspectivas para o ensino de língua portuguesa. 2015. 171f. Dissertação (Mestrado em Letras) - Universidade do Estado do Rio Grande do Norte. Faculdade de Letras e Artes. Programa Mestrado Profissional em Letras, Pau dos Ferros, RN, 2015.

MACHADO, B. dos S. C. A prática de leitura, produção de textos e análise linguística no ensino de língua portuguesa: uma proposta de organização do cotidiano escolar na perspectiva dos multiletramentos. Revista Linguas \& Letras - Unioeste - Vol. 15 - No 31 - 2014.

MARCUSCHI, L. A. Gêneros textuais: definição e funcionalidade. In: DIONÍSIO, A. P.; MACHADO, A. R.; BEZERRA, M. A. (Orgs.). Gêneros textuais e ensino. Rio de Janeiro: Lucerna, 2002, p. 19-36.

MOITA LOPES, L. P. da. Linguística aplicada e a vida contemporânea: problematização dos construtos que têm orientado a pesquisa. In: MOITA LOPES, L. P. (org.). Por uma Linguistica Aplicada Indisciplinar. São Paulo: Parábola, 2006.

. Oficina de linguística aplicada: a natureza social e educacional dos processos de ensino/aprendizagem de línguas. Campinas, SP: Mercado de Letras, 1996.

Pesquisa interpretativista em Linguística Aplicada: a linguagem como condição e solução. D.E.L.T.A.,10 (2): 329-338, 1994.

MOZDZENSKI, L. Intertextualidade verbo-visual: como os textos multissemióticos dialogam?. Bakbtiniana, Rev. Estud. Discurso, vol.8 n. 2, São Paulo July/Dec. 2013. Disponível em: http://www.scielo.br/pdf/bak/v8n2/11.pdf. Acesso em: Acesso em: 06 fev. 2018.

NOVELLINO, M. O. Imagens em movimento: a multimodalidade no material para o ensino de inglês como língua estrangeira 2011. 243f. Tese (Doutorado) - Pontifícia Universidade Católica do Rio de Janeiro, Departamento de Letras, 2011.

OLIVEIRA, F. C. C. de. Um estudo sobre a caracterização do gênero redação do Enem. 2016. 166f. Tese (Doutorado em Linguística), Universidade Federal do Ceará, Programa de Pós-Graduação em Linguística, Fortaleza, 2016.

OLIVEIRA JÚNIOR, O. B. A redação do Enem e o sucesso escolar entre alunos do Ensino Médio. Anais do VI Simpósio Internacional de Ensino da Lingua Portuguesa - Lingua, Texto e Ensino. v. 3. n. 1. 2014. Disponível em: <http://www.ileel.ufu.br/anaisdosielp/wp-content/uploads/2014/11/163.pdf>. Acesso em: 24 mar. 2018.

ORMUNDO, J. da S. Reconfiguração da linguagem na globalização. 2007.127f. Tese (Doutorado em linguística) - Programa de Pós-graduação em linguística, Departamento de Linguística, Português e Línguas Clássicas, Universidade de Brasília, Brasília, 2007. 
PAIVA, F. J. de O. As concepções de alunos do Ensino Médio sobre o uso de estratégias de leitura. In: OLIVEIRA, K. C. C. et al. Aprendendo na travessia: dilemas do ensino-aprendizagem na escola básica. 1. ed. Teresina: EDUFPI, 2013. p. 76-89.

O professor de língua portuguesa como agente de letramento em anos iniciais do ensino fundamental: uma análise sobre o uso de estratégias de leitura. Travessias (Unioeste. Online), v. 10, p. 125-146, 2016. Disponível em: < http:/ / e-revista.unioeste.br/index.php/travessias/article/view/13843/9823>. Acesso em: 02 out. 2017.

.; LIMA, A. M. P. Do texto multissemiótico ao texto verbal: uma análise de propostas de redação do Enem sob a perspectiva do letramento visual crítico. Humanidades \& inovação, v. 5, p. 188-213, 2018. Disponível em: <https://revista.unitins.br/index.php/humanidadeseinovacao/article/view/591>. Acesso em: 14 mar. 2018.

PAULINELLI, M. de P. T.; FORTUNATO, G. C. A redação do Enem à luz dos gêneros discursivos e textuais. RevLet - Revista Virtual de Letras, v. 08, no 01, jan/jul, 2016. Disponível em: <http://www.revlet.com.br/artigos/367.pdf>. Acesso em 14 mar. 2018.

PELLEGRINI, T. Narrativa verbal e narrativa visual: possíveis aproximações. In: . et al. Literatura, cinema e televisão. São Paulo: Ed. Senac São Paulo / Instituto Itaú Cultural, 2003, p.14-35.

PENNYCOOK, A. Linguística aplicada dos anos 90: em defesa de uma abordagem crítica. In: SIGNORINI, I.; CAVALCANTI, M. C. (Orgs.). Linguística aplicada e transdisciplinaridade: questões e perspectivas. Campinas: Mercado de Letras, 2007.

PIMENTA, S. M. O.; SANTANA, C. D. A. Multimodalidade e semiótica social: o estado da arte. In: MATTE, A. C. F. (org.). Lingua(gem), texto, discurso: entre a reflexão e a prática. Rio de Janeiro: Lucena; Belo Horizonte, MG: FALE/UFMG, v.2, 2007, pp. 152 $-174$.

REINALDO, M. A. G. M. Que concepções teóricas de gênero textual estão subjacentes às questões discursivas do Enem? Revista do GELNE, Natal/RN, v. 4, n.1, 2002. Disponível em: <https://periodicos.ufrn.br/gelne/article/view/9134/6488>. Acesso em: 21 mar. 2018.

RESENDE, V. M. Análise de discurso crítica: reflexões teóricas e epistemológicas quase excessivas de uma analista obstinada. In: perspectivas. Campinas: Pontes, 2017. . (Org.). Análise de discurso crítica: outras

SILVINO, F. F. Letramento Visual. ANAIS - Seminários Teóricos Interdisciplinares do SEMIOTEC - I STIS, nov./2012. Disponível em: <www.periodicos.letras.ufmg.br/index.php/stis/article/download/2116/2714>. Acesso em: 12 jan. 2018.

SOARES, M. Letramento: um tema em três gêneros. Belo Horizonte: Autêntica. 2004. 
TEIXEIRA, S. A. Da redoma para o público: análise do processo de recontextualização do discurso científico em divulgativo no Jornal da UFV. 2013. 135f. Dissertação (Magister Scientiae), Programa de Pós-Graduação em Letras da Universidade Federal de Viçosa, Viçosa, MG, 2013.

THE NEW LONDON GROUP. A pedagogy of multiliteracies: designing social futures. Harvard Educational Review, v. 66, n. 01, p. 60-92, spring, 1996.

VAN LEEUWEN, T. Discourse and practice: new tools for critical discourse analysis. Oxford: Oxford University Press, 2008. . Introducing Social Semiotics. New York: Routledge, 2005.

VELOSO, F.O.D. Pesquisa em multimodalidade: Por uma abordagem sociossemiótica. In: GONÇALVES, A. V.; SILVA, W. R.; GÓES, M. L. de S. Visibilizar a linguística aplicada: Abordagens teóricas e metodológicas. Campinas, SP: Pontes, 2014, p. 155-180.

Recebido em: 17/09/2018. Aprovado em: 01/02/2019. 